\title{
Phase III: Implementation and Operation of the Repository
}

\author{
Quarterly Report \\ April 1 - June 30, 1998
}

Work Performed Under Contract No.: DE-FG22-97BC14847

\author{
For \\ U.S. Department of Energy \\ Office of Fossil Energy \\ Federal Energy Technology Center \\ P.O. Box 880 \\ Morgantown, West Virginia 26507-0880
}

By

American Geological Institute

4220 King Street

Alexandria, Virginia 22302-1502 


\section{Disclaimer}

This report was prepared as an account of work sponsored by an agency of the United States Government. Neither the United States Government nor any agency thereof, nor any of their employees, makes any warranty, express or implied, or assumes any legal liability or responsibility for the accuracy, completeness, or usefulness of any information, apparatus, product, or process disclosed, or represents that its use would not infringe privately owned rights. Reference herein to any specific commercial product, process, or service by trade

name, trademark, manufacturer, or otherwise does not necessarily constitute or imply its endorsement, recommendation, or favoring by the United States Government or any agency thereof. The views and opinions of authors expressed herein do not necessarily state or reflect those of the United States Government or any agency thereof. 


\title{
NATIONAL GEOSCIENCE
}

\section{DATA REPOSITORY SYSTEM}

\section{PHASE III: IMPLEMENTATION AND OPERATION OF THE REPOSITORY \\ PROGRESS REPORT DE-FG22-97BC-14847}

\author{
2nd Quarter \\ April-June, 1998 \\ Submitted by the \\ AMERICAN GEOLOGICAL INSTITUTE \\ to the
}

Office of Fossil Energy, U.S. Department of Energy

$$
\text { July } 1998
$$

American Geological Institute, 4220 King Street, Alexandria, VA 22302-1502

(703) 379-2480 Fax: (703) 379-7563 


\section{NGDRS Phase III - Implementation \\ First Quarter Progress Report}

July 1998

\section{$\underline{\text { Overview }}$}

The metadata catalog was brought online for public access May 14, 1998. Since then dozens of users have registered and began to access the system. The system was demonstrated at the AAPG annual meeting in Salt Lake City and the EAGE (European Association of Geoscientists and Engineers) annual meeting in Leipzig, Germany. Hart Publications and PTTC "NetworkNews" have published articles about the metadata catalog, and articles for the AAPG Explorer and GSA Today are being developed.

A back-up system at AGI headquarters was established. In support of the metadata catalog system, a leased-line Internet connection and two servers were installed. Porting of the GeoTrek server software to the new systems has begun. The back-up system will be operational during the $3^{\text {rd }}$ quarter of 1998 and will serve the NGDRS needs during periods when access to the site in Houston is down. Additionally, experimentation with new data types and deployment schemes will be tested on the system at AGI.

The NGDRS has picked-up additional endorsements from the American Association of State Geologists, the MMS Outer Continental Shelf Policy Committee, and a new endorsement is being formulated by the AAPG Core Preservation Committee for consideration by the AAPG Executive Committee.

The Texas Bureau of Economic Geology (BEG) is currently geocoding the well locations for the metadata catalog. Also, they have solicited proposals for the development of a core inventory control system that will work hand-in-hand with GeoTrek. A contract for that system will probably be given during the $3^{\text {rd }}$ quarter of 1998. The Texas Railroad Commission proposes to test the application of GeoTrek for accessing data in a joint project with the BEG.

Several data transfer projects are underway. Vastar has committed to the transfer of 2D Appalachian seismic lines to the NDGRS clearinghouse. Receiving repositories have been identified and the final preparations are being made for transfer to these public repositories. Discussions have been initiated with the State of Oregon concerning listing their 400 oil and gas well and 50 geothermal well cores and logs on the metadata catalog. Additionally, discussions continue with the Stapleton Development Corporation concerning the transfer of facilities in Denver for use as a central core repository. A letter of intent for the facility's transfer is being reviewed. 


\section{Program Activities Summary}

\section{Establishing the Clearinghouse}

\subsection{Project status}

The ongoing component projects for the NGDRS and their status:

\begin{tabular}{|l|l|c|}
\hline \multicolumn{1}{|c|}{ Project Name } & \multicolumn{1}{c|}{ Project Type } & Status \\
\hline Central Core Facility Project & Transfer of Core and Cuttings & Underway \\
\hline Well Log Data Tape Conversion Project & Transfer of Digital Data & Not defined \\
\hline Seismic Data Tape Conversion Project & Transfer of Digital Data & Underway \\
\hline BEG Project & Electronic Database Transfer & Underway \\
\hline PGS Project & Electronic Database Transfer & Completed \\
\hline Kansas Geological Survey Project & Electronic Database Transfer & Delayed \\
\hline Mobil Seismic Sales Project & Electronic Database Transfer & Not defined \\
\hline Metadata Repository Infrastructure & Creation of the Metadata Repository & Completed \\
\hline Metadata Repository Utilization & Utilization and Operations of the Metadata Repository & Completed \\
\hline Mineral Management Services (MMS) & Electronic Database Transfer & Completed \\
\hline Oklahoma Geological Survey (OGS) & Electronic Database Transfer & Completed \\
\hline Eastern Gulf Region PTTC & Electronic Database Transfer & Completed \\
\hline
\end{tabular}

\subsection{BEG - Conversion and Installation}

Under contract with AGI through the NGDRS program, the Bureau of Economic Geology has hired a number of students to geocode the well log and core location information. Currently the BEG data is listed by county. Using information from the Texas Railroad Commission, the actual locations of the wells from which these data were acquired are being geocoding. The updated locations will be added to the GeoTrek installations both in the NGDRS and at the BEG.

Additionally, the BEG has requested proposals to develop a core inventory control application to work hand-in-hand with GeoTrek. Once completed, AGI will be able to market the core inventory management system together with GeoTrek in an effort to increase participation by public core repositories across the country.

\subsection{MMS}

The field descriptions for the MMS databases have been edited to improve their intuitiveness. This activity was completed before the public release of the metadata catalog, and additional revisions may be made depending upon feedback from the system's users.

\subsection{Oregon Department of Geology and Mineral Industries}


Discussions have begun between the Oil and Gas group of the Oregon Department of Geology and Mineral Industries and AGI for listing of their core and well log holdings on the NGDRS metadata catalog. They hold cores and records for 400 oil and gas wells and 50 geothermal wells.

Oregon's metadata is in digital format and should be readily integrated into the metadata catalog. However, the data is currently stored in MapInfo and they are working on exporting it to a simple table format.

\subsection{West Virginia Geological Survey}

Initial contact was made concerning placing the West Virginia Geological Survey's Oil \& Gas metadata on the NGDRS metadata catalog. The WVGS currently has a database of 123,715 wells; however, they charge a \$10/hour data access fee. Listing in the NGDRS metadata catalog is counter to this policy and does not seem reasonable at this time. However, it has been noted that the data for West Virginia is in digital form and easily integrated into the metadata catalog when it may become more appropriate to pursue this avenue.

\subsection{Ice Cores}

In late June, the current database for ice core holdings was examined. The listings for ice core data is distributed across several research facilities. The quality and accessibility of the data make them prime candidates for joining the NGDRS and listing their holdings in the metadata catalog. Discussions with the various research groups holding ice core data will be initiated in the $3^{\text {rd }}$ quarter of 1998.

\subsection{Contribution of Seismic Reflection Data}

Vastar has agreed to contribute over 4000 digital seismic reflection field tapes to the NGDRS. The collection represents some 700 seismic lines extending along the Appalachian Thrust Belt from Southern New York State to Northern Alabama. The 9-track seismic tapes will be transcribed to new high-density tape media prior to transfer to the NGDRS. We are continuing discussions with Vastar and are preparing for the tape transcription to facilitate the transfer.

\subsection{Establishing a central core repository}

Based on our studies, we estimate that between 4 and 5 million boxes of cores and cuttings are currently being held in private corporate repositories. The majority of these holdings are available for transfer to public repositories; however, most public repositories are already near capacity. Accommodating such a major transfer of data from the private to the public sector requires identification of substantial new repository space.

AGI is continuing discussions with the Stapleton Development Corporation to develop a letter of intent for the donation of a former hanger to the NGDRS to serve as a core/cutting research repository. 
On June 11, Marcus Milling and Christopher Keane met with Edith Allison and Guido DeHoratius at the Department of Energy Headquarters in Washington. The meeting was to discuss the AGI proposal to use $\$ 100,000$ of the DOE funds in the pending phase III grant towards performing the site evaluation and characterization of the Stapleton property as a potential National Geoscience Data Repository and Research Center. A general agreement was reach that AGI could include the cost of the Stapleton site characterization in the grant proposal, as it represented a clear effort towards the transfer and preservation of cores and cuttings.

\section{Utilizing the metadata repository}

\subsection{Operating the Metadata Catalog}

On May 14, 1998, the metadata catalog for the NGDRS became operational and open to the public. At launch, the following databases were made available:

- Fairfield Seismic

- A2D Well Logs

- MMS Well Logs

- Alabama Eastern Gulf PTTC Well Logs

- BEG Well Logs

- BEG Cores

- Oklahoma Geological Survey Cores

- MMS Block and Lease Boundaries

PGS has opted to delay listing their holdings on the metadata catalog until they can provide sufficient quantity and quality of sample seismic sections for online viewing. We expect the PGS holdings to be available through the metadata catalog during the Q3 of 1998.

The statistics for the use of the metadata catalog and the associated web pages concerning the NGDRS are as follows:

\begin{tabular}{|l|c|c|c|}
\hline & May & June & YTD \\
\hline NGDRS Website Hits & 874 & 2934 & 3808 \\
\hline Unique Visitors to NGDRS & 46 & 165 & 211 \\
\hline Unique GeoTrek Users & 15 & 33 & 48 \\
\hline Number of GeoTrek Searches & 479 & 406 & 885 \\
\hline Total GeoTrek databases transactions & 3100 & 3755 & 6855 \\
\hline
\end{tabular}

\subsection{Identifiable Clients}

A wide variety of US education, government, and private organizations have accessed the NGDRS web pages and metadata catalog, as well as users from around the world.

\section{US Accesses}

Arco 
Arizona Dept. of Transportation

Boeing

Cal State Fullerton

Chesapeake Energy

IRIS

Monterrey Bay Aquarium Research Institute

Muskingum University

New Mexico Tech

Penn State University

PI-Dwights

Radian Corporation

Smithsonian Institution

Tribune Corporation (Print and Broadcast Media)

Union Texas Corporation

University of Arizona

University of California, Riverside

University of Illinois, Champaign

University of Minnesota

University of Rhode Island

University of Texas

University of Tulsa

University of Utah

U.S. Army

U.S. Dept. of Interior Office of Surface Mining

USGS

Valpraiso University

\section{Foreign Accesses}

Australia

Canada

Germany

Italy

Switzerland

Netherlands (Shell Oil)

Taiwan

United Kingdom

Ukraine

\subsection{Advertising the metadata catalog}

Access to the metadata catalog is expected to steadily increase, particularly later in the $3^{\text {rd }}$ Quarter of 1998. Summer is historically a slow period for many websites, and we believe that activity will markedly increase during the second half of the year. In an effort to promote the metadata catalog, several actions have occurred during the second quarter. 
Notification of the site becoming available was made to the USENET community, particularly the sci.geo.* newgroups. A notice was also sent to several geoscience-related listservs, and links and indexing were requested from all of the major search and content sites such as Yahoo! and AltaVista.

On May 17 in Salt Lake City, Marcus Milling and Christopher Keane attended the AAPG Core Preservation Committee meeting to discuss the status of the NGDRS. A consensus to encourage the AAPG Explorer to run an article about the metadata catalog and the NGDRS was reached from this meeting.

Additionally, the metadata catalog was demonstrated at the AAPG annual meeting Salt Lake City and the EAGE (European Association of Geoscientists and Engineers) annual meeting in Leipzig, Germany. Additionally, both Hart Publications and the PTTC have written articles about the metadata catalog.

\subsection{Software}

The GeoTrek server software is currently stable and has been deployed in production environments. The browser software is also very stable, especially on Windows 95, Windows NT 4.0, Solaris 2.4, and Linux 2.0.31.

\subsection{Back-up System Deployment}

A back-up system is being configured at AGI headquarters in Alexandria, Virginia. The main web pages for the NGDRS are hosted at this site, and an installation of GeoTrek, including a mirror of the databases held in Houston will be available. This system will be available in cases where access to the NGDRS metadata catalog in Houston is unavailable from the rest of the Internet. Additionally, experiments with new data types, such as publication citations will be explored on the AGI site.

A leased-line connection was established to AGI headquarters, and two Intel-based Linux 2.0.31 servers installed. A porting effort of the GeoTrek server-side software to the Linux platform for use as the back-up system is currently being planned, and should be completed during the $3^{\text {rd }}$ quarter of 1998.

\subsection{Interaction with NASA's Global Change Master Directory}

In follow-up to the meeting in January, Christopher Keane met with Todd Byrd, the geology specialist on the Global Change Master Directory, during the AAPG annual meeting in Salt Lake City. The GCMD plans to write complete DIFs for the data holdings of the NGDRS metadata catalog. This capability will enable users to search on subject-based key words for the appropriate data sets within the NGDRS. This also provides an interface from the National Spatial Data Infrastructure (NSDI) to the NGDRS metadata catalog. 
By working with the GCMD personnel, the NGDRS will be more usable to users as the scope and number of data sets increase. Additionally, the availability of linkages into the NGDRS metadata catalog will hopefully increase traffic. 